\title{
Percursos teórico-metodológicos de pesquisadoras iniciantes: análises de escritas de professoras em contexto de formação continuada
}

\author{
Recorridos teórico-metodológicos de investigadoras principiantes: \\ análisis de escrituras de profesoras en contexto de formación continuada
}

\author{
Theoretical-methodological trajectories of beginning researchers: \\ analyzes of teachers writings of in-service teacher education context
}

Luiza Kerstner Souto ${ }^{1}$

Josiane Jarline Jäger ${ }^{2}$

\begin{abstract}
Resumo
Este trabalho descreve, analisa e reflete sobre a transformação dos focos de análise de escritas de professoras orientadoras de estudo. Para isso, aborda-se as análises embasadas em perspectivas teóricas e metodológicas, apresentando resultados e discussões realizadas. Mostra-se como os focos de análise foram se transformando em função da ampliação de referenciais teóricos e estudos realizados ao longo de anos de pesquisa, o que permitia que se olhasse para os dados a partir de diferentes perspectivas. O processo metodológico começou inspirado em uma análise de conteúdo e progrediu para uma análise de cunho mais interpretativo, processo que promoveu um avanço nos resultados e sentidos atribuídos às escritas analisadas. Elenca-se esse processo de transformação das análises como fundamental para formação das autoras como pesquisadoras iniciantes, permitindo-as pensar diferente do que se raciocinava e ampliar o olhar a partir da interação e leitura do/com o mundo, consigo e com o outro. As leituras e os encontros orientadores foram elementos que constituíram e reverberaram na experiência enquanto pesquisadoras iniciantes. A disposição para (trans)formar-se também foi elencada como essencial para que os focos de análise e problematizações fossem se modificando no decorrer da pesquisa.
\end{abstract}

Palavras-Chave: escritas de professoras; formação de professores; iniciação à pesquisa; percursos metodológicos.

\section{Resumen}

Este trabajo describe, analiza y reflexiona acerca de la transformación de los enfoques del análisis de las escrituras de profesoras orientadoras de estudios. Para esto, se abordan análisis basadas en perspectivas teóricas y metodológicas, presentando los resultados y las discusiones realizadas. Se muestra como los enfoques del análisis se fueron transformando por el hecho de la ampliación de los referenciales teóricos y de los estudios realizados a lo largo de años de investigaciones, lo que ha permitido que se vean a los datos a partir de diferentes perspectivas. El proceso metodológico comienza inspirado en un análisis de contenido y ha progresado hacia un análisis más interpretativo, proceso que ha promovido un avance en los resultados y sentidos asignados a las escrituras analizadas. Se ha relacionado este proceso de transformación de los análisis como algo fundamental para la formación das autoras como investigadoras principiantes, las permitiendo pensar diferente de lo que se razonaba y que ha ampliado la mirada a partir de la interacción y lectura del y/o con el mundo, con uno mismo y con el otro. Las lecturas y los encuentros de orientación fueron elementos que constituyeron y reflejaron (han reverberado) en la experiencia como investigadoras principiantes. La predisposición para (trans)formarse

\footnotetext{
${ }^{1}$ Mestranda em Educação, Licenciada em Pedagogia; Universidade Federal de Pelotas; Pelotas, RS, Brasil; luizaksouto@gmail.com

${ }^{2}$ Mestranda em Educação, Licenciada em Pedagogia; Universidade Federal de Pelotas; Pelotas, RS, Brasil; josianejager@gmail.com
} 
también se ha tenido como esencial para que los enfoques del análisis y las problematizaciones fuesen modificándose en el recorrido de la investigación.

Palabras claves: escrituras de profesoras; formación de profesores; iniciación a la investigación; itinerarios metodológicos.

\begin{abstract}
This paper describes, analyzes and reflects about the focus transformation in analysis of teachers writings. These analyzes are presented based on theoretical and methodological perspectives, showing results and discussions. The analysis focus transformed because the theoretical references and studies expanded during years of research. That allowed looking at the data from different perspectives. The methodological process inspired by content analysis progressed to an interpretative analysis. This process promoted an advance in the results and meanings attributed to the analyzed writings. The analyzes transformation is fundamental for beginning researchers formation, allowing to think differently from what was thought and to expand the view through interaction and reading of / with the world, with itself and with others. The readings and the guiding encounters were elements that constituted and reverberated in the experience as beginners researchers. In addition, the openness to transform itself was essential for the focus of analysis modify in the course of the research.
\end{abstract}

Keywords: teachers writing; in-service teacher education; research initiation; methodological paths.

\title{
1. Introdução
}

Existem momentos na vida onde a questão do saber se se pode diferentemente do que se pensa, e perceber diferentemente do que se vê, é indispensável para continuar a olhar ou a refletir (FOUCAULT, 1998, p.13).

Foucault fala da importância do saber pensar e olhar diferentemente do que pensava e via para o ato de continuar a olhar e a refletir. Assim também entendemos o processo enquanto pesquisadoras. É indispensável refazer os caminhos já percorridos e analisarmos se podemos pensar e olhar de outro modo para aquilo que estávamos olhando, além de entender como fomos transformando nosso olhar.

É nesse contexto que a construção desse trabalho acontece. Refizemos e repensamos o caminho de nossa pesquisa, realizada enquanto pesquisadoras iniciantes, para identificar questões e acontecimentos que influenciaram a experiência de nosso pensamento. Observamos que a atribuição de sentidos para os dados analisados se modificou conforme fomos alterando o ponto de vista sob o qual olhávamos. Isso significa que, ao abandonar a primazia do método e entrar numa perspectiva epistemológica, abrindo-se às possibilidades que os dados mostravam, ampliaram-se as perspectivas analíticas. Essa abertura tornou-se possível conforme fomos expandindo as leituras, estudos e encontros com professores e pesquisadores que nos interpelavam com perguntas. Nesse processo fomos assumindo o lugar de pesquisadoras que pensam e constroem razões e sentidos para o que veem. 
Para isso, abordamos as análises embasadas em perspectivas teóricas e metodológicas, apresentando resultados e discussões realizadas, vinculadas à um Projeto de Pesquisa que investiga a formação continuada de professores, no âmbito do Observatório da Educação/CAPES, de uma Universidade pública do Rio Grande do Sul. Ao longo de nossa atuação, nos ocupamos com a organização do Banco de Textos de Professoras (BTP). Os textos que compõem este banco foram coletados durante os encontros de formação continuada do Programa Pacto Nacional pela Alfabetização na Idade Certa, em específico as formações realizadas, entre 2013 e 2014, no âmbito de uma das universidades públicas do estado do Rio Grande do Sul. Os textos coletados versavam sobre questões relativas às temáticas trabalhadas na formação e foram aplicadas por formadores e pesquisadores ligados ao projeto de pesquisa.

Em nossas análises, nos debruçamos sobre os textos das professoras orientadoras de estudo que versavam sobre as temáticas avaliação e planejamento. Realizamos análises das escritas problematizando questões relacionadas aos conhecimentos dos professores e como eles desenvolvem os mesmos, intencionando, a partir disso, pensar como a formação inicial e continuada influencia as ações pedagógicas dos professores e como estes vão constituindo sua identidade e profissionalidade docente.

Em 2013, as coletas foram realizadas antes da formação ter abordado a temática que se referia à questão mobilizadora de escrita, servindo como um diagnóstico dos conhecimentos que as OEs possuíam, apesar de ser possível ter ocorrida, anteriormente, pelas OEs, a leitura dos cadernos de formação que versavam sobre as temáticas. A coleta realizada em 2014, aconteceu após terem sido trabalhadas as respectivas temáticas. Na tabela a seguir, estão as questões relativas às temáticas planejamento e avaliação.

Tabela 1 - Questões sobre planejamento e avaliação (2013 e 2014)

\begin{tabular}{|c|c|c|}
\hline QUESTÕES 2013 & SIGLA & QUESTÕES 2014 \\
\hline $\begin{array}{c}\text { Como avalias as aprendizagens? Como } \\
\text { verificar se os objetivos traçados foram } \\
\text { alcançados? }\end{array}$ & AVA & $\begin{array}{c}\text { Que aspectos e princípios devem ser } \\
\text { considerados no processo de planejamento do } \\
\text { ensino nos anos iniciais? }\end{array}$ \\
\hline
\end{tabular}


RELACult - Revista Latino-Americana de Estudos em Cultura e Sociedade

Revista Latinoamericana de Estudios en Cultura y Sociedad | Latin American Journal of Studies in Culture and Society V. 05, ed. especial, abr., 2019, artigo no 1278| claec.org/relacult |e-ISSN: 2525-7870

Que princípios devem ser considerados no processo de planejamento do ensino nos anos iniciais?

O que devemos considerar para planejar o processo de alfabetização e ensino/aprendizagem de Língua Portuguesa?
E, no seu ponto de vista, como a avaliação está articulada ao processo de planejamento de ensino?

Fonte: tabela elaborada pelas autoras

Em 2013 foram coletados 315 textos na temática planejamento e 368 textos na temática avaliação. Em 2014, as temáticas da avaliação e planejamento foram associadas em uma questão, entendendo as duas temáticas como constitutivas da organização do trabalho pedagógico do professor. As respostas a essa questão totalizaram 240 textos. A seguir, na Tabela 2, apresentamos as turmas, temáticas e anos de coleta abarcados em cada análise. Como pode ser observado, pelo menos uma mesma turma foi sempre mantida:

Tabela 2 - Turmas, temáticas e anos de coleta dos textos analisados

\begin{tabular}{|c|c|c|c|c|c|c|c|c|c|}
\hline \multicolumn{2}{|c|}{$\begin{array}{l}1^{\mathrm{a}} \text { análise } \\
2014\end{array}$} & \multicolumn{2}{|c|}{$\begin{array}{l}2^{\mathrm{a}} \text { análise } \\
2015\end{array}$} & \multicolumn{2}{|c|}{$\begin{array}{l}3^{\mathrm{a}} \text { análise } \\
2016\end{array}$} & \multicolumn{2}{|c|}{$\begin{array}{l}4^{\mathrm{a}} \text { análise } \\
2016\end{array}$} & \multicolumn{2}{|c|}{$\begin{array}{l}5^{\mathrm{a}} \text { análise } \\
2017\end{array}$} \\
\hline \multicolumn{2}{|c|}{ PPALP } & \multicolumn{2}{|c|}{$\begin{array}{c}\text { PPALP } \\
\text { PPALPeAVA }\end{array}$} & \multicolumn{2}{|c|}{ AVA } & \multicolumn{2}{|c|}{$\begin{array}{c}\text { PPALP } \\
\text { PPALPeAVA }\end{array}$} & \multicolumn{2}{|c|}{$\begin{array}{c}\text { PPALP } \\
\text { PPALPeAVA }\end{array}$} \\
\hline Turma & Coleta & Turma & Coleta & Turma & Coleta & Turma & Coleta & Turma & Coleta \\
\hline A & 2013 & A & 2013 & A & 2013 & A & 2013 & A & 2013 \\
\hline B & 2013 & A & 2014 & & & A & 2014 & A & 2014 \\
\hline \multirow[t]{4}{*}{$\mathrm{C}$} & 2013 & & & & & & & $\mathrm{D}$ & 2013 \\
\hline & & & & & & & & $\mathrm{D}$ & 2014 \\
\hline & & & & & & & & $\mathrm{E}$ & 2013 \\
\hline & & & & & & & & E & 2014 \\
\hline
\end{tabular}

Fonte: tabela elaborada pelas autoras. 
Na sequência, descreveremos as indagações que mobilizaram as análises das escritas das OEs nas temáticas avaliação e planejamento. Apresentaremos os resultados e discussões realizadas, mostraremos as metodologias e teóricos que colaboraram nas análises, e, por fim, refletiremos sobre esse processo de transformação da forma de olhar para os dados e discutilos.

\section{Repensando os percursos da pesquisa}

As análises realizadas iniciaram em 2014, tendo como material de pesquisa 64 textos de OEs, de 3 turmas de formação de 2013, que versavam sobre as questões de planejamento. Os textos foram analisados com o objetivo de ver quais concepções e princípios as professoras apresentavam como importantes para o trabalho no ciclo de alfabetização.

Como metodologia, utilizamos a análise de conteúdo amparada nos estudos de Moraes (1999). Esse tipo de análise consiste em uma ferramenta para descrever e interpretar conteúdos de textos e documentos, sendo guiada pelos seguintes processos: 1) Preparação das informações; 2) Unitarização ou transformação do conteúdo em unidades; 3) Categorização ou classificação das unidades em categorias; 4) Descrição; 5) Interpretação (MORAES, 1999, p. 4).

Dessa forma, realizamos a leitura atenta dos textos das OEs a fim de observar quais ideias eram as mais recorrentes e estavam relacionadas aos princípios teórico-metodológicos do processo de planejamento. A partir disso, estabelecemos as unidades temáticas conforme as concepções identificadas, transformando-as em categorias. Após a categorização, descrevemos e interpretamos as concepções das professoras.

Como resultados da análise, encontramos pelo menos 4 concepções mais recorrentes nas escritas em torno do ato de planejar: (1) Valorizar os conhecimentos prévios das crianças; (2) Considerar as hipóteses de aquisição da escrita; (3) Observar os eixos norteadores do ensino da Língua Portuguesa; (4) Garantir os direitos de aprendizagem.

A partir dessa análise de 2014, consideramos que as OEs apresentavam conhecimentos sobre os princípios que conduzem o processo de planejamento e que o PNAIC poderia se constituir numa importante política de formação continuada; porém, ainda percebíamos a necessidade de ampliar a dimensão conceptual sobre os princípios orientadores do processo de planejamento no ciclo de alfabetização, principalmente por sabermos, através dos cadernos de formação, que as formações do PNAIC discutiam princípios, concepções e práticas em torno do planejamento e entendermos que a ampliação conceitual como impulsora de novas práticas é uma necessidade contínua na formação de professores,. 
Em 2015, voltamos aos textos para observar tendências que se mantinham ou se alteravam em relação às concepções e princípios do planejamento e da avaliação, analisando 39 textos produzidos pelas OEs em 2013 e 2014, de uma das turmas que havíamos analisado em 2014. Para isso, fizemos fichamentos dos cadernos de formação do PNAIC (anos 1, 2 e 3 - unidades 1 a 8 e caderno de avaliação), buscando mapear as principais concepções em torno das temáticas planejamento e avaliação, a fim de cotejá-las com aquilo que era trazido nas escritas das OEs.

Essas concepções foram organizadas em uma tabela contendo 4 eixos: conceito (definições de planejamento e avaliação), aspectos didáticos (princípios orientadores e como fazer/exemplos, evidenciando as orientações didáticas para o professor e os exemplos de como desenvolver tal orientação) e concepção de ensino-aprendizagem (concepções de cunho teórico do processo de ensino-aprendizagem assumidas pelo PNAIC).

A partir da organização das concepções dos cadernos de formação na tabela, fizemos a leitura dos textos das professoras, procurando identificar se suas concepções iam ao encontro daquilo que os cadernos traziam ou não, fazendo comparações dos princípios e concepções de planejar e avaliar nos cadernos de formações com as escritas das professoras. Nesse momento, nossa metodologia ainda estava baseada na análise de conteúdo, na qual líamos os textos, encontrávamos unidades temáticas transformando-as em categorias e, por fim, descrevíamos e refletíamos sobre os conteúdos dos textos.

Nessa análise, como concepções e princípios do planejamento e avaliação mais recorrentes nos 39 textos, tanto de 2013 como de 2014, foram encontrados: (1) Realidade; (2) Objetivos; (3) Avaliação; (4) Direitos de Aprendizagem. Pudemos perceber que as concepções apresentadas pelas OEs iam ao encontro dos cadernos de formação, trazendo em suas escritas cópias literais ou reescritas dos conteúdos dos cadernos. Além disso, as concepções eram apresentadas de forma encadeada, evidenciando a imprescindibilidade de contemplá-las no processo de planejamento; porém, em suas escritas, as OEs não apontavam elementos práticos, de sua ação pedagógica, que poderiam subsidiar e ilustrar suas escritas.

Esses aspectos foram levantados por nós, ao percebermos que, além de cópias e elementos reescritos dos cadernos de formação, o modo de escrever e elencar os princípios mostrava uma interdependência entre os princípios para o planejamento. Nesse momento ainda não compreendíamos que o próprio contexto formativo e a forma da questão mobilizadora da escrita poderia influenciar as respostas sem elementos da ação pedagógica das professoras. Apesar de considerarmos os cadernos de formação como influenciadores das 
escritas, ainda olhávamos para as escritas sem considerar de forma mais interdependente o contexto de sua produção.

Em 2016, examinamos 22 textos produzidos em 2013, da mesma turma já analisada em 2015, porém, nesse momento, a análise se deu em torno das questões sobre avaliação com o objetivo de analisar as concepções trazidas pelas professoras sobre o tema, cotejando-as com as concepções de avaliação trazidas nos cadernos de formação do PNAIC.

Nessa análise, novamente nos baseamos na análise de conteúdo, buscando verificar se as concepções dos cadernos de formação e das OEs eram parecidas ou não, sem atentar muito para outros elementos que as próprias escritas poderiam trazer como problematização do contexto formativo e do modelo de formação do PNAIC.

As concepções de avaliação mais recorrentes nos textos das OEs foram: (1) Avaliação diagnóstica e contínua; (2) Avaliação para (re)planejamento e (3) Avaliar a prática do professor; (4) Ver se os objetivos foram cumpridos.

Nessa análise de 2016, percebemos que as professoras escreviam em seus textos concepções bastante semelhantes àquilo que estavam nos cadernos de formação, apresentando poucos elementos críticos sobre aquilo que estavam estudando nas formações; não descrevendo muito sobre suas ações e experiências como professoras para falarem de aspectos da ação pedagógica. Isso também nos fez pensar em quais espaços a própria formação do PNAIC (e as formações continuadas em geral) estava proporcionando às professoras para que estes elementos do âmbito do seu exercício profissional fossem inseridos nas reflexões realizadas durante os encontros de formação.

Até este momento, nossas análises eram influenciadas por referenciais que tratavam sobre a aquisição da língua escrita e sobre como se aprende, referenciais amparados fortemente no campo da psicologia educacional. Além disso, estudávamos sobre a organização do trabalho pedagógico, especificamente, sobre o planejamento e os conteúdos relativos à alfabetização. Destacamos: as ideias referentes ao sujeito ativo na construção dos conhecimentos e hipóteses de aquisição da língua escrita (Ferreiro e Teberosky, 1999); a ideia de que os novos conhecimentos são estruturados a partir do que já se sabe (Piaget, 1973; Vygotsky, 1994); as modalidades organizativas do trabalho pedagógico (Nery, 2007); o sistema de escrita alfabética (Morais, 2012) e o planejamento (Veiga, 2011). Esses referenciais também formavam a base epistemológica dos cadernos de formação utilizados no contexto formativo do PNAIC, sendo os construtos teóricos mais utilizados o construtivismo e o sócio-interacionismo. 
Ainda em 2016, as análises começaram a tomar outros rumos. A escrita começou a ser entendida por nós como elemento potente de análise em contextos formativos, pois, se em um primeiro momento achávamos que as escritas deveriam revelar o que as professoras "sabiam" ou não em relação aos conteúdos da formação, em um segundo momento de análise, começamos a atentar para o que a escrita poderia nos revelar sobre o processo formativo das professoras e sobre o próprio contexto de formação do PNAIC.

Dessa forma, analisamos 39 textos dos anos 2013 e 2014 de uma mesma turma de formação já analisada em 2015, identificando os tipos de processos de escrita que as professoras revelavam em seus textos, refletindo sobre a prática da escrita como estratégia formativa. Utilizamos como base de análise os tipos de processos de escrita enunciados por Hatton e Smith (1995 apud MIZUKAMI, 2002): redação descritiva, descrição reflexiva, reflexão dialógica e reflexão crítica.

Hatton e Smith, ao analisarem textos de participantes de um curso de formação de professores, identificaram quatro tipos de processos de escrita, a seguir explicitados: Redação descritiva - apresenta o registro de eventos ou de exemplos descritos na literatura e não contém elementos de justificativa para o que é descrito; Descrição reflexiva - expõe eventos e elementos de justificativa de forma descritiva, amparada em julgamentos pessoais ou de literatura, evidenciando reflexões com base em uma ou mais perspectivas; Reflexão dialógica - tipo de discurso consigo próprio e exploração de possíveis razões para os fatos apresentados, indicando, de forma analítica e integrativa, possíveis alternativas para explicar o fato ou estabelecimento de hipóteses; Reflexão crítica - abrange argumentação para tomada de decisões ou análise de eventos e apresenta uma preocupação de que os eventos não sejam apenas explicados por diversas perspectivas, mas também influenciados por contextos históricos, sociais e políticos mais amplos.

A partir desse referencial de tipos de escrita, focamos nos conteúdos das respostas e nas concepções trazidas sobre avaliação e planejamento e, além disso, no modo de escrita das professoras. Como resultados, verificamos que a maioria dos textos de 2013 estava em um processo de redação descritiva, pois havia cópia literal de conteúdos dos cadernos de formação ou tentativas de reescrita.

Com isso, levantamos duas hipóteses: a primeira foi que o próprio contexto de formação poderia ter limitado as escritas, visto que as OEs estavam em contato direto com os cadernos de formação que tratavam desses assuntos de forma mais conceitual, além do fator de obrigatoriedade de estudo dos cadernos de formação. Já a segunda hipótese, problematizava se a formulação das questões teria limitado as respostas das professoras, pois 
perguntavam sobre princípios do ato de planejar e avaliar, não deixando claro que as escritas poderiam ser ilustradas com exemplos e ações pedagógicas realizadas pelas professoras.

Assim, consideramos que seria possível, em função de uma cultura escolar instituída, que as OEs somente respondiam o que a pergunta pedia. Além disso, as professoras poderiam pensar (ou sentir) que estavam sendo avaliadas quanto aos conteúdos trabalhados na formação e por isso não transgrediam trazendo elementos da prática e avançando numa escrita mais reflexiva.

Já nas escritas de 2014, verificamos uma maior evidência de escritas descritivas reflexivas. A nossa hipótese é que pode ter ocorrido uma qualificação dos processos de análise e escrita sobre os conhecimentos envolvidos no trabalho docente, como o planejamento e a avaliação. Percebemos que os estudos realizados nos encontros de formação podem ter gerado a construção de conhecimentos e reflexões, mas isso não garante que as professoras estão instrumentalizadas para pensar sobre a ação docente, pois o princípio da reprodutibilidade de conhecimentos e experiências não se aplica na educação, visto que a professora não é uma técnica que aplica procedimentos, mas sim uma intelectual que a partir da reflexão sobre suas ações produz conhecimentos sobre, na e a partir da prática pedagógica.

Isso nos levou a atentar para a complexidade de analisar a escrita de professoras em contexto formativo como fonte de razões pedagógicas (SHULMAN, 2014) e tomadas de decisão do cotidiano da sala de aula. Além disso, é preciso considerar que a escrita, apesar de ser uma atividade presente em contextos formativos, é tarefa complexa, pois a escrita sistematiza ações e pensamentos pedagógicos na relação com conhecimentos de diversas bases (SHULMAN, 2014) e por vezes os coloca em questão, demandado um reelaborar-se continuamente. Por estas razões, entendemos que é uma estratégia importante para explicitar os raciocínios das professoras e reconstruí-los, o que nos instigou a continuar olhando para a escrita como estratégia formativa potente em contexto de formação continuada de professoras para compreender o pensamento pedagógico e os movimentos formativos proporcionados.

Assim, as análises realizadas em 2016 e ampliadas em 2017 foram movidas por estudos teóricos que refletem sobre a escrita como estratégia formativa (FREIRE, 1996; KRAMER, 2001; NÖRNBERG e SILVA, 2014). Na análise ampliada feita em 2017, examinamos 117 textos, mantendo uma das turmas, cujos textos foram examinados em todas as análises feitas, e foram escolhidas outras duas turmas. Analisamos os textos produzidos nas formações de 2013 e 2014 com o objetivo de, além de identificar os processos de escrita das OEs, discutir aspectos trazidos por elas sobre seus conhecimentos para o trabalho docente, 
buscando entender e interpretar o que estes apontam para a formação continuada, no PNAIC, e para a formação de professores, em geral.

As questões mobilizadoras foram as seguintes: $\mathrm{O}$ que escritas de professoras participantes de um curso de Formação Continuada indicam sobre o processo formativo? O que constitui um movimento formativo? A formação continuada do PNAIC constitui-se em/por um movimento formativo?

$\mathrm{Na}$ análise realizada em 2017, começamos a atentar para o que as escritas das OEs poderiam nos apontar sobre o movimento formativo das professoras, bem como no que se constituiria um movimento formativo das mesmas. Nesse período, o método de análise começou a se reconfigurar inspirado em uma abordagem mais interpretativa. Com inspiração em uma análise temática (MINAYO, 1993) e interpretativa (GRAUE, 2003).

A análise temática demanda uma leitura compreensiva e exaustiva do conjunto de materiais, a exploração do material para análise constituindo núcleos de sentido, as unidades temáticas e a construção de uma síntese interpretativa que dialoga com os objetivos, questões e pressupostos da pesquisa (MINAYO, 1993). A análise interpretativa (GRAUE, 2003) é emaranhada e holística, os passos transmitem informação uns aos outros, numa tentativa de relacionar o todo e as partes, a empiria e os conceitos. Esse encontro entre pesquisadoras e textos - empiria, conceitos, contexto formativo, geram novas percepções. Nesse processo pudemos reconstruir e ampliar os sentidos e às razões para o que percebíamos na empiria, atentando para compreensão de aspectos diferenciadores e imprevistos (PÉREZ GÓMEZ, 1998), indo além da identificação de padrões, visto que os movimentos formativos observados não eram predominantes no conjunto dos textos. Contudo, são movimentos que podem potencializar a transformação da ação e do pensamento pedagógico, gerando desenvolvimento da profissionalidade, sendo por isso evidenciados no processo de análise.

Assim, essa construção do método de análise mais próximo de uma abordagem interpretativa possibilitou que ampliássemos nossa forma de olhar e construir razões para os textos das professoras. Dessa forma, foi crescendo o espaço para temáticas que surgiam em torno das questões propostas e de que modo essas temáticas apareciam, atentando para diferenças e descontinuidades que poderiam se constituir tendências formativas importantes para qualificar processos formativos. Assim, avançamos em relação ao tipo de metodologia anterior, que verificava se as respostas das OEs respondiam às questões propostas e como respondiam.

Percebemos que a maioria das produções escritas das professoras estava em um processo de redação descritiva. Essas escritas não apresentavam argumentos mais claros e 
reflexivos que dessem elementos de justificativas para suas ações e princípios sobre os quais escreviam. Algumas OEs apresentavam elementos de justificativa, articulando mais a sua escrita em relação aos princípios que regiam suas ações, indo para um processo de descrição reflexiva, mas isso foi mais raro no conjunto de textos analisados.

Pensando em fatores que podem ter influenciado esse tipo de resposta das OEs, reafirmamos a hipótese formulada em análises anteriores de que a forma como as perguntas mobilizadoras foram realizadas pode ter limitado os processos reflexivos das professoras, materializados na escrita. Essa hipótese foi de alguma forma constatada ao ampliarmos os dados e ao refazermos a problematização inicial. Em outra hipótese, indicamos que as professoras não discorriam sobre sua prática por não perceberem que o conteúdo de seu trabalho docente fosse um conhecimento valorizado e, portanto, passível de conduzir a reflexão sobre uma determinada temática.

Ao mesmo tempo, constatamos alguns movimentos formativos a partir da escrita das OEs. Os movimentos formativos se estabeleceram quando as OEs (1) empreenderam fugas a questão mobilizadora e refletiram em sua escrita elementos do cotidiano escolar, demonstrando uma prática de liberdade intelectual; (2) estabeleceram relação com teorias ou teóricos ou quando colocaram em evidência diversas bases de conhecimento que mobilizavam seu trabalho; (3) escreveram sobre o princípio da progressão do ensino e da aprendizagem, o que demanda processos de replanejamento e reflexão. Esse processo de re-planejamento é tomado como forma de resistência à tentativa de controle sobre o trabalho do professor. A resistência é praticada na ação de repensar sua ação pedagógica para que as crianças possam avançar na construção de conhecimentos.

Também foi possível observar o que pode ser caracterizado como um desenvolvimento da profissionalidade docente, pois as escritas de 2013 encontravam-se majoritariamente em um processo de redação descritiva e, em 2014, aumentaram as escritas descritivo reflexivas, indicando uma evolução na forma de escrever sobre os conhecimentos mobilizados para o planejamento. Na totalidade dos 117 textos, as OEs quase não fizeram referência aos teóricos da área da educação para subsidiar suas escritas. Essa constatação abre a seguinte reflexão: como os processos formativos estão possibilitando condições para que as professoras estabeleçam relações teórico-práticas sobre sua ação pedagógica, engendrando outro movimento formativo que permita o reelaborar suas razões para ação?

Assumimos a posição de que "é o conhecimento teórico que permite ler as situações da escola, criando condições para compreendê-las e, assim, tomar decisões no sentido de encaminhar a ação educativa" (NÖRNBERG; CAVA, 2017, p.60), pois entendemos que é a 
teoria que permite compreender a complexidade dos fenômenos educativos e que fornece subsídios para que a ação seja repensada e reiniciada.

Sendo assim, para que o professor possa avançar na explicitação de suas razões e raciocínios pedagógicos, é preciso que os espaços formativos ofereçam estudos consistentes que coloquem em diálogo a ação e o pensamento pedagógico dos professores para que as teorizações sejam ressignificadas, refutadas ou reconstruídas. Dessa forma, os processos de raciocínio e tomadas de decisão no cotidiano de seu trabalho poderão ser qualificados, avançando-se nos argumentos e possibilidades de ação frente às complexidades envolvidas na ação educativa.

A partir de então, nosso olhar começou a ficar atento às "fugas" ao tema da questão, entendendo-as como práticas de liberdade intelectual e procurando potencialidades formativas em processo, o que denominamos como movimentos formativos. Essa mudança no olhar e nas percepções sobre os elementos constitutivos das escritas aconteceu pela ampliação dos referenciais teóricos e metodológicos que orientaram e inspiraram as análises, constituídos por: Nörnberg e Cava (2015), com a ideia de que a aprendizagem da docência se dá na interação com o outro, tendo como importante espaço de formação o coletivo de professores; Nóvoa (2009) e Imbernón (2011), quando referem sobre a necessidade de que sejam fornecidas as condições materiais e humanas para que os professores ocupem o lugar da produção de conhecimentos; Mizukami (2002), quando explicita sobre a construção do conhecimento profissional que é processual, um processo contínuo; Garcia, Vieira e Hypólito (2005), que demonstram as resistências que as professoras praticam em relação às tentativas de controle sobre seu processo de trabalho; e, Shulman (2014), quando explica sobre as bases de conhecimento do professor e sua defesa de que a utilidade de um conhecimento está no seu valor para julgamento e ação. Os referenciais metodológicos constituíram-se nessa etapa por Minayo (1993), Graue (2003) e Pérez Gómez (1998), como já explicitado anteriormente.

Pudemos perceber que a mudança na forma de olhar para os dados, bem como a ampliação dos referenciais teóricos e metodológicos fizeram com que um caminho metodológico alternativo fosse se construindo. Assim, destacamos a importância de não termos nos limitado a um método de análise e de termos nos aberto ao que os dados, os referenciais e os encontros e questionamentos com outros nos provocaram, podendo assim, ir além do pensado e percebido. Sobre esses aspectos refletiremos na seção a seguir.

\section{Conclusões}


Ao percorrermos os caminhos teórico-metodológicos das análises realizadas podemos destacar, pelo menos, três elementos importantes. O primeiro é a transformação da metodologia para lidar com os dados da pesquisa. Fomos notando que ao longo da nossa trajetória precisávamos nos afastar da forma de olhar os dados para que eles pudessem nos revelar novas coisas. Assim, nos abrimos a uma metodologia mais interpretativa, que também nos permitiu ter mais "autonomia" enquanto pesquisadoras, entendendo melhor o próprio ato de pesquisar na construção de razões para o que víamos. Isso nos fez compreender que, no âmbito da pesquisa, não é necessário que o método venha antes do conteúdo, ao contrário disso, muitas vezes a abertura à multiplicidade de significados é que possibilita a construção de uma metodologia mais adequada aos dados que temos. Nesse sentido, é importante que o método não se anteponha à experiência do pesquisador com os materiais de análise (NAJMANOVICH, 2003).

Dada a complexidade e a dinamicidade dos fenômenos educativos, precisamos renunciar a ilusão de um saber absoluto e, na construção da pesquisa, à medida que às compreensões sobre os fenômenos educativos vão se atualizando, suscitam-se transformações metodológicas. Assim, chegamos a um segundo elemento a ser destacado, a mudança na nossa compreensão conceitual sobre formação e trabalho docente, o que também nos influenciou na transformação da metodologia de pesquisa.

Ao longo das análises, fomos optando por atentar para aquilo que o professor sabe e faz em sua ação pedagógica, suas potencialidades e seus conhecimentos, ao invés de procurarmos pelas faltas, apontando aquilo que o professor parecia não saber em suas escritas.

Dessa forma, se antes olhávamos para a escritas com um olhar apropriador (LARROSA, 2016), o olhar do deveria ser, das faltas, das sentenças e das classificações; passamos a construir um olhar dadivoso (LARROSA, 2016), que se abre ao texto e encontra a realidade como ela é. Esse processo permitiu que valorizássemos as descontinuidades dos movimentos formativos encontrados nas escritas, entendendo os aspectos diferenciadores como práticas de liberdade intelectual. Essa conceitualização sobre os fenômenos da formação de professores foi construída e modificada a partir da ampliação de referenciais teóricos estudados e pelas próprias experiências formativas que tivemos enquanto professoras em formação.

Se em um primeiro momento tínhamos uma ideia mais ligada a um modelo formativo de "transmissão e atualização de conhecimentos", amparado em uma racionalidade técnica, que entende o professor como aplicador de conhecimentos adquiridos nas formações (CANDAU, 1996); conforme fomos estudando e entendendo a complexidade da formação de 
professores, começamos a enxergar a possibilidade de um modelo de formação continuada que compreende o professor como intelectual que através da reflexão sobre, para e a partir da ação pedagógica e por meio da interconexão com estudos teóricos e diálogos entre pares (NÓVOA, 2009), constrói seu conhecimento profissional.

Assim, passamos a olhar para as respostas das OEs às questões propostas de maneira diferente, entendendo que os conhecimentos das professoras não se limitavam às respostas que davam para as questões e que da mesma forma, a formação do PNAIC não poderia ser avaliada somente pelas professoras terem demonstrado ou não os conceitos trabalhados durante a formação, visto que há uma tensão entre o dizer e o fazer. Os conhecimentos explicitados nem sempre condizem com as práticas e, por vezes, as práticas realizadas não são comunicadas em sua dinamicidade e complexidade através da escrita (MEIRIEU, 2002).

Por fim, um terceiro elemento a destacar é a importância da experiência formativa que nos possibilitou adentrar em movimentos transformativos enquanto pesquisadoras. A experiência formativa permitiu darmos um novo sentido, um novo olhar para aquilo que já estávamos olhando. Ato que envolveu sensibilidade de olhar para si, para o outro e a partir disso renovar o olhar, dando outros sentidos para os dados. Ao mesmo tempo, a experiência só acontece quando nos abrimos a tê-la (LARROSA, 2017). Nesse sentido, podemos elencar dois elementos que nos ajudaram nessa abertura para a experiência: as leituras e os encontros orientadores, provocativos e/ou inspiradores que geraram em nós movimentos (trans)formativos.

Sobre a leitura e os encontros, podemos pensar com e a partir dos pensamentos profícuos de Larrosa (2016). O autor define a experiência da leitura como o diálogo entre o que o texto diz e o que não diz. O dito do texto aponta para o que não está escrito e, assim, constrói sentidos. A leitura interpela o leitor tirando-o de si, o coloca em questão. A leitura chama para que vá além de si mesmo. Ao tirar de si mesmo, o leitor torna-se outro, diferente do que era antes, a leitura o transforma.

Dessa maneira, consideramos que todas leituras de referenciais teóricos, de indicações de colegas e professores foram essenciais para que nosso olhar fosse interpelado e modificado aos poucos em relação aos dados de análise. Com o aprofundamento de conhecimentos sobre formação de professores e os temas em torno de nossas análises, conseguimos avançar naquilo que estávamos problematizando e vimos novas possibilidades de interpretações dos textos das professoras, criando caminhos metodológicos alternativos para as análises.

Acreditamos que os encontros também foram importantes para nossa experiência formativa, pois foram momentos que nos proporcionaram o pensar com o outro, a partir do 
pensamento do outro, num processo de aprender com (LARROSA, 2016, p. 143). Foram nesses momentos, nas reuniões de orientação, nos encontros do grupo de pesquisa, nas apresentações em eventos, que pudemos fazer o exercício de pensar sobre o que estávamos analisando, expor nossas reflexões e inquietações e, sobretudo, sermos interpeladas pelas perguntas do outro, para, assim, firmar concepções e desconstruir outras que tínhamos até então. Os encontros com outros constituíram-se como orientadores, provocativos e inspiradores, gerando um pensamento (des)construtivo.

\section{Referências}

BRASIL. Pacto Nacional pela Alfabetização na Idade Certa. Cadernos de formação. Brasília: MEC, SEB, 2012. (Obra completa)

CANDAU, V. M. F. Formação continuada de professores: tendências atuais. In: REALLI, A.M.M. MIZUKAMI, M.G.N. Formação de professores tendências atuais. São Carlos: Edufscar, 1996. p.139-152. (Capítulo de livro)

FERREIRO, E.; TEBEROSKY, A. A psicogênese da língua escrita. Porto Alegre: Artes Médicas, 1999. (Obra completa)

FOUCAULT, M. Introdução. In: . História da sexualidade II:. Rio de Janeiro: Graal, 1998. v. 2. p.7-26 (Capítulo de livro)

FREIRE, M. (coord.). Instrumentos metodológicos I. São Paulo: Espaço Pedagógico, 1996. (Obra completa)

GARCIA, M. VIEIRA, J. HYPÓLITO, A. As identidades docentes como fabricação da docência. Educação e Pesquisa, São Paulo, v. 31, n. 1, p. 45-56, jan./abr. 2005. Disponível em: http://www.scielo.br/pdf/ep/v31n1/a04v31n1.pdf . Acesso em: 01 nov. 2018. (Artigo em Periódico Digital)

GRAUE, M. E. A interpretação em contexto. In. GRAUE, M. E.; WALSH, D. J. Investigação etnográfica com crianças: teorias, métodos e ética. Trad. Ana Maria Chaves. Lisboa: Fundação Calouste Gulbenkian, 2003. p. 189-224. (Capítulo de livro)

IMBERNÓN, F. Formação docente e profissional formar-se para a mudança e a incerteza. 9. ed. São Paulo: Cortez, 2011. (Obra completa)

KRAMER, S. Alfabetização, leitura e escrita: Formação de professores em curso. São Paulo: Ática, 2001. (Obra completa)

LARROSA, J. Tremores: escritos sobre experiência. 1ed. $3^{\text {a }}$ reimp. Belo Horizonte: Autêntica Editora, 2017. (Obra completa)

LARROSA, J. Pedagogia profana: danças, piruetas e mascaradas. 5ed. 3.reimp. Belo Horizonte: Autêntica Editora, 2016. (Obra completa) 
MEIRIEU, P. A pedagogia entre o dizer e o fazer: A coragem de começar. Porto Alegre: Artmed, 2002. (Obra completa)

MINAYO, M. C. de S. O desafio do conhecimento: pesquisa qualitativa em saúde. 2ed. Rio de Janeiro: Hucitec, 1993. (Obra completa)

MIZUKAMI, M. da G. N. et al. Escola e aprendizagem da docência: processos de investigação e formação. 1a ed. São Carlos: EdUFSCar, 2002. (Obra completa)

MORAES, R. Análise de Conteúdo. Revista Educação, Porto Alegre, v.22/n.37/ p.7-32, 1999. Disponível

em: http://pesquisaemeducacaoufrgs.pbworks.com/w/file/fetch/60815562/Analise\%20de\%20conte \%C3\%BAdo.pdf . Acesso em: 01 nov. 2018. (Artigo em Periódico Digital)

MORAIS, A. G. Sistema de escrita alfabética. São Paulo: Editora Melhoramentos, 2012. (Obra completa)

NAJMANOVICH, D. O feitiço do método. In: GARCIA, R. L. (org.). Método; Métodos; Contramétodo. São Paulo: Cortez, 2003. p.25-62. (Capítulo de livro)

NERY, A. Modalidades Organizativas do Trabalho Pedagógico: Uma possibilidade. In: BEAUCHAMP, J., PAGEL, S.D. e NASCIMENTO, A. R. (Org.) Ensino Fundamental de 9 anos. Brasília. $2007 . \quad$ DEC/SEB, em: http://portal.mec.gov.br/seb/arquivos/pdf/Ensfund/ensifund9anobasefinal.pdf . Acesso em: 01 nov. 2018. (Artigo em Documento Digital)

NÖRNBERG, M.; CAVA, P. P. O que é da ordem do teórico e do prático? Reflexões sobre formação de professores em contexto de estágio. In: NÖRNBERG, M. (org.). Formação em contextos de estágio e desenvolvimento profissional. São Leopoldo: Oikos, 2017. Estudo 2 (p.53-72). (Capítulo de livro)

NÖRNBERG, M.; CAVA, P. P. A aprendizagem compartilhada da ação docente. In: $37^{\mathrm{a}}$ REUNIÃO NACIONAL DA ANPED. 04 a 08 de outubro de 2015, UFSC - Florianópolis. Disponível em: http://www.anped.org.br/sites/default/files/trabalho-gt08-4274.pdf . Acesso em: 01 nov. 2018. (Trabalho em Anais de Congresso)

NÖRNBERG, M; SILVA, G. F. Processos de escrita e autoria sobre a ação docente enquanto prática formativa. Educar em Revista, Curitiba, n. 54, p. 185-202, out/dez, 2014. Disponível em: http://www.scielo.br/pdf/er/n54/a12n54.pdf . Acesso em: 01 nov. 2018. (Artigo em Periódico Digital)

NÓVOA, A. Professores: Imagens do futuro presente. Lisboa: Educa, 2009. (Obra completa)

PÉREZ GÓMEZ, A.I. Compreender o ensino na escola: modelos metodológicos de investigação educativa. In: SACRISTÁN, J.G.; PÉREZ GÓMEZ, A.I. Compreender $e$ transformar o ensino. $4^{\mathrm{a}}$ ed. Porto Alegre: Artmed, 1998. p.99-115. (Capítulo de livro)

PIAGET, J. Psicologia e Epistemologia: Por uma teoria do conhecimento. Rio de Janeiro: Forense Universitária, 1973. (Obra completa) 
SHULMAN, L. Conhecimento e ensino: fundamentos para a nova reforma. Tradução de Leda Beck. Cadernos Cenpec, v. 4, n. 2, p.196-229, dez. 2014. Disponível em: http://cadernos.cenpec.org.br/cadernos/index.php/cadernos/article/view/293/297 . Acesso em: 01 nov. 2018. (Artigo em Periódico Digital)

VEIGA, I. Aula: Gênese, dimensões, princípios e práticas. 2ed. Campinas: Papirus, 2011. (Obra completa)

VYGOTSKY, L. S. A formação social da mente: o desenvolvimento dos processos psicológicos superiores. São Paulo: Martins Fontes, 1994. (Obra completa) 